\title{
Fabrication and Evaluation of Agave Americana Leaf Fiber
}

\author{
L.Suvitha ${ }^{1}$ \\ \{ suvithalatchupathi@gmail.com ${ }^{1}$ \} \\ Department of Fashion Technology, PSG College of Technology,Coimbatore-641004,India ${ }^{1}$
}

\begin{abstract}
The manmade fibers are predominant to the natural fibers and also it has its own importance in many of the applications. The natural fibers are widely used due to their surplus availability and due to its environment friendly nature. These environment friendly fibers are mostly used in the manufacturing of composites, fibers, ropes and cordages. Fibers, extracted from leaves of Agave Americana plant are cellulosic in nature and has unique properties when compared to other natural cellulosic fibers. In this study the fibers are extracted using retting process and the impurities are removed using scouring and bleaching process. The scouring and bleaching process was carried out in a bath. Then the fibers are tested. The agave fibers are spun into yarn by using flyer spinning machine. The yarn is converted into fabric by using handloom weaving machine. Then the fabric is dyed by using cold brand reactive dyes. Then the fabrics were given a finishing treatment by using silicone enzyme to soften the fabric. Then the fabrics were tested.
\end{abstract}

Keywords: Agave Americana Fibers, Flyer Spinning, Reactive Dyeing, Sisal, Water Retting.

\section{Introduction}

Natural fibers are comfortable, healthy, totally biodegradable and renewable- renewed by nature and human ingenuity for millennia. As the natural fibers grow in different climatic zone and also the carbon dioxide $\left(\mathrm{Co}_{2}\right)$ is recycled in contrast to synthetic fibers. Few of the natural fiberse.g. bast fibers can be used for cleaning the soil which is polluted by heavy metals. Other than cotton, silk, and wool, many more green fibers may be used in textile for producing comfortable clothing which are also completely recyclable and biodegradable once their lifetime is over. The fibers that are most widely used in textile reinforcement are flax, jute, hemp, kenaf, sisal, ramie, abaca, coir, cabuya, pineapple, bamboo, and many others which can be extracted, processed, modified and used as textile composites.

\section{Materials And Method}

\section{A. Fibre Extraction}

Agave Americana fibres are extracted from leaves obtained from Agave Americana plant. Initially the leaves are cut down from the Agave Americana plant. The piths in the fibres is been removed by mild beating and it is been washed in the running water to remove the other 
impurities present in the fibre. These leaves were dried in the sunlight. Then the fibres are peeled manually from the stem and taken for testing.

\section{B. Water Retting}

Retting is the process of removal of plant tissue from the fibers by immersing the fibers in water. This process also promotes microbial growth on the extracted natural cellulosic fibers more easily. The retting process leads to pollution as it is carried out using waterborne bacteria to break down the cellular tissue and gums which surround the fiber. Water retting is anaerobic processes whereby tanks and other stagnant water ret rapidly become depleted of oxygen encouraging the development of an anaerobic flora. The water retting process for plants is carried out using pectinase enzyme which is a natural enzyme produced from bacteria. The retting process is carried out in specially constructed tank to maintain the process under control and also to maintain the standards that are formed by the environmentalists. The natural cellulosic fibers production and processing methods should be environmental friendly. As the water retting is carried out using bacteria temperature and bacterial content of the leave retted in tanks can be more carefully controlled and the timing can be maintained accordingly so that the river pollution can be eliminated.

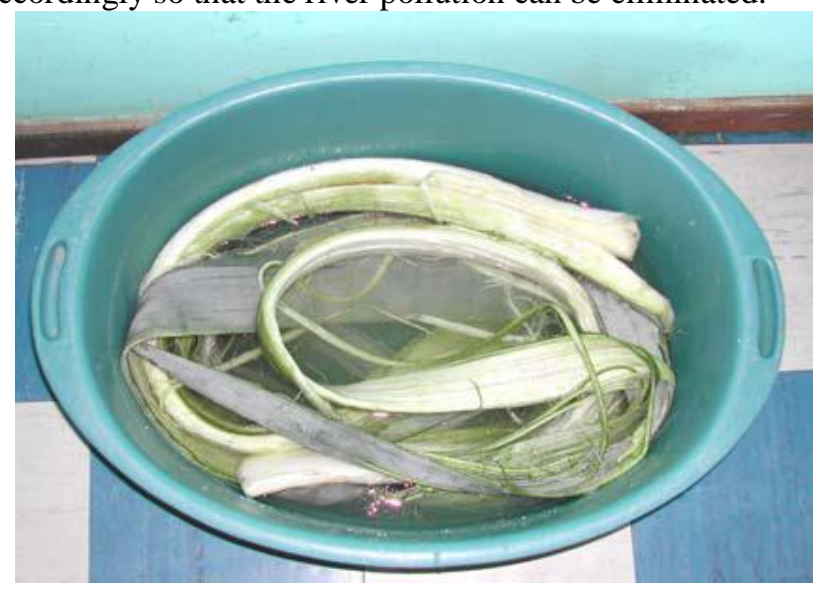

Fig.1. Retting of Agave Americana

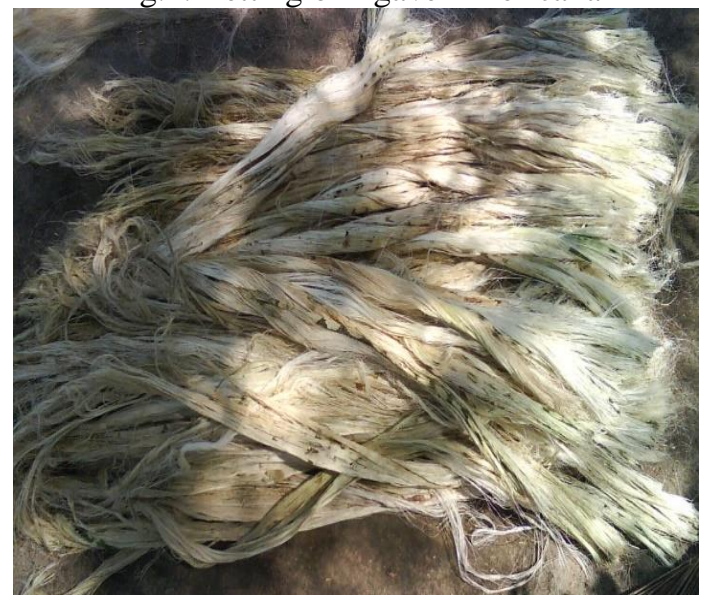

Fig.2. Extracted Fibers 


\section{C. $\quad$ Scouring of Agave fibre}

Agave fibres were put in a bath containing 0.2 to 0.3 gpl of sodium hydroxide and $0.5 \mathrm{gpl}$ non ionic detergent solutions at $40^{\circ} \mathrm{c}$ to $45^{\circ} \mathrm{c}$ for 30 minutes maintaing the m:l ratio at 1:20. The scoured fibre was then thoroughly washed with tap water and dried at room temperature.

\section{Bleaching of Agave fibre}

Agave fibres were bleached in a bath containing $0.5 \mathrm{gpl}$ of hydrogen peroxide at $40^{\circ} \mathrm{c}$ to $45^{\circ} \mathrm{c}$ for 30 minutes maintaining the m:l ratio at 1:20. The bleached fibre was thoroughly washed with tap water and dried at room temperature.

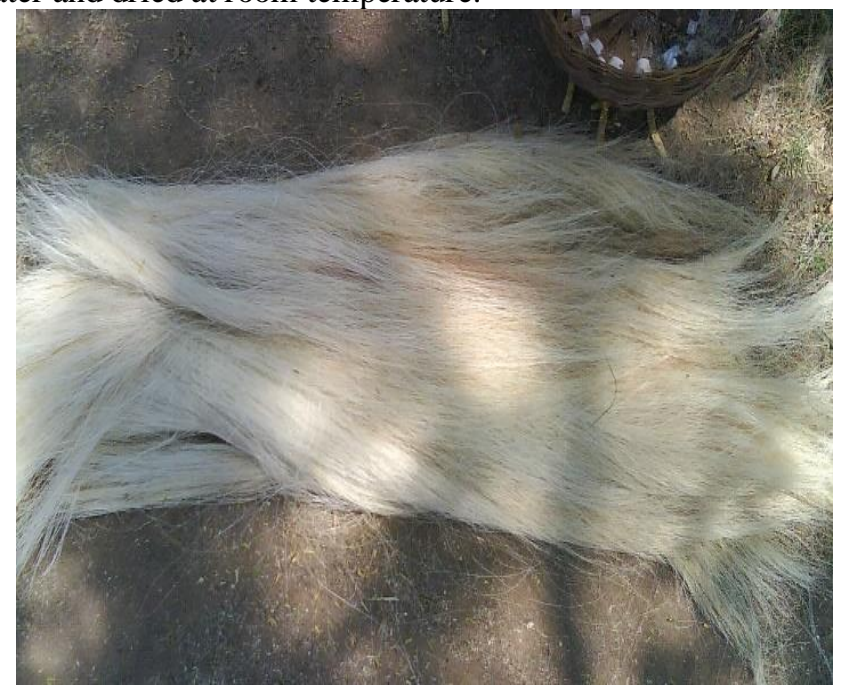

Fig.4. Bleached Fibers

\section{Spinning Process}

The agave fibres were softened using Turkey red oil 2.5\%. Fibres of 10 inch and processed through breaker and finished card.For proper blending two passages were provided at finished card. The finisher card sliver is processed through three passages of Gill drawing frame for improving fibre parallelisation.

In finisher carding and each gill drawing machine, mechanised crimping(by slotted roller and over feed mechanism) is given at the delivery point to impart some sort of cohesion to the fibres in sliver.The third drawing sliver is fed to the flyer spinning machine for manufacturing agave yarns.

The flyer spinning machine used in jute spinning system is suitable for producing $100 \%$ agave yarns of runnage $3500 \mathrm{~m} \backslash \mathrm{Kg}$ and $4500 \mathrm{~m} \backslash \mathrm{Kg}$. 


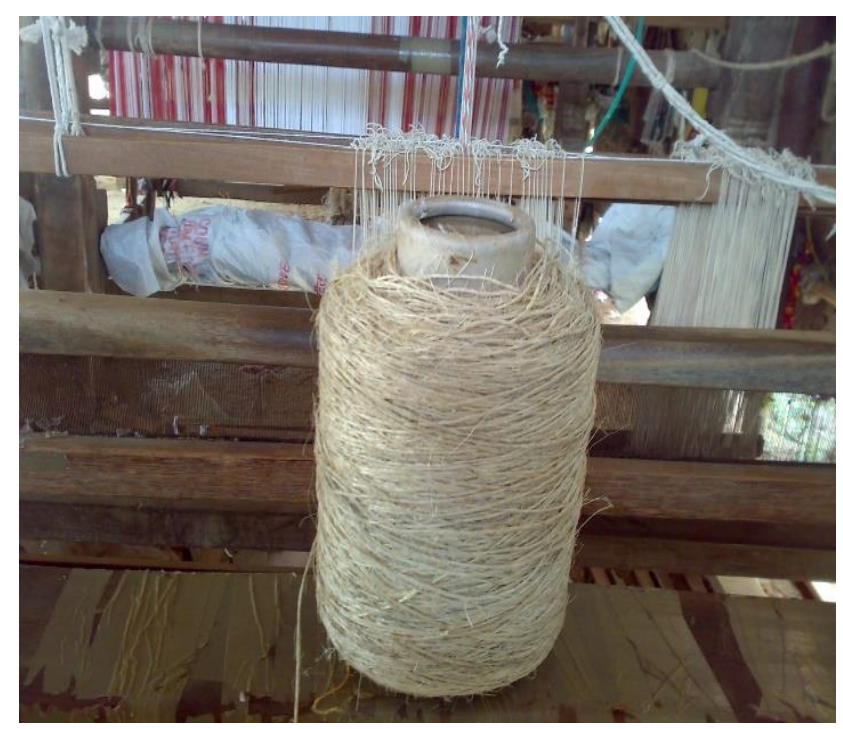

Fig.5. Spun Yarn

\section{Weaving}

The weaving of agave yarns are carried out in handloom weaving. The fabric is plain weaved according to the required dimension

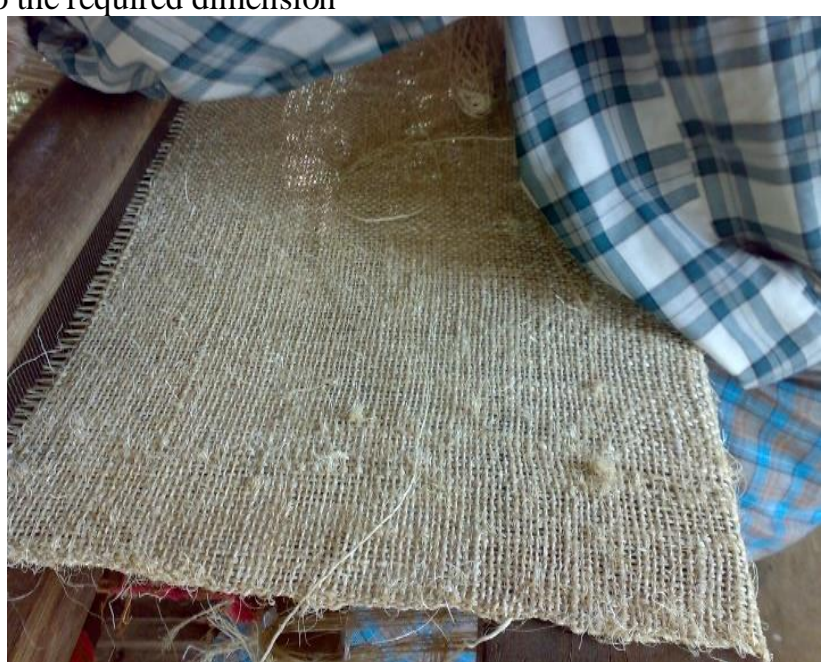

Fig.6. Agave fibers made into Fabric

\section{Dyeing}

The agave fabric is dyed by using cold brand reactive dyes.

Recipe 


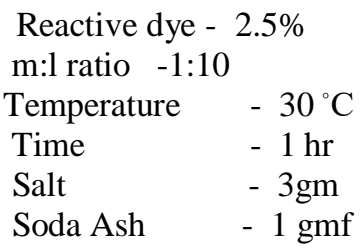

After dyeing the fabric is washed with cold water and the fabric is subjected to neutralising treatment using Acetic Acid. Then the fabric is washed and is treated with fixing agent to fix the dye. Then the fabric washed with hot water and cold water. Then the fabric is dried and is taken for testing.

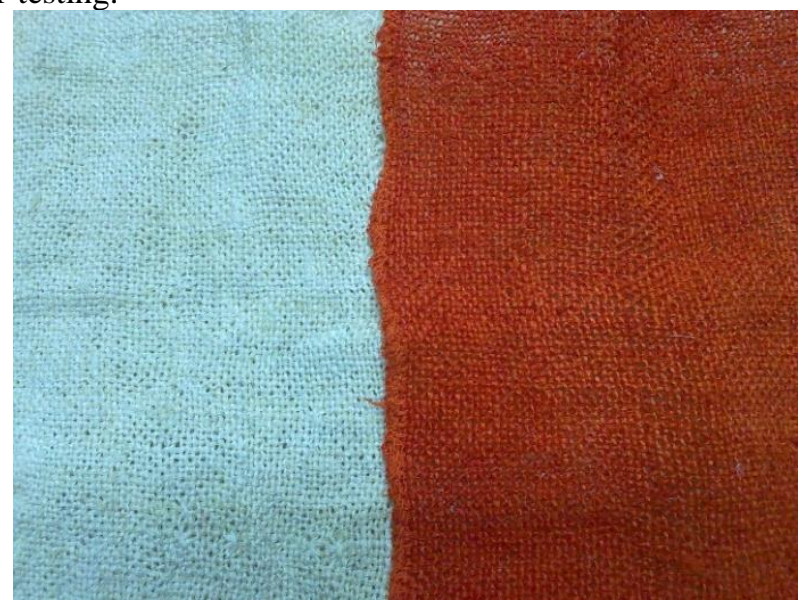

Fig.7. Reactive dyed Fabric

\section{Finishing of Agave Fabric}

The fabric produced from natural leaf fibre is normally stiff. To reduce the stiffness from the fabric finishing agave fabric is carried out.

Agave fabric was put in to a bath containing 1-2\% silicone finisher for $30 \mathrm{~min}$ at room temperature. The M:L ratio was kept at 1: 10 . Then the fabric is washed in cold water at room temperature and dried.

\section{Results and Discussion}

\section{A. Fiber Length And Diameter}

The fiber diameter measured using projection microscope which shows wider variation in dimensions starting from 15 micron meter upwards. The average micron was found to be about $17.73 \mu \mathrm{m}$.

\section{B. Linear Density}

The denier values of the natural fibers extracted from the leaves of Agave plant appear to vary to a large extent, which could be realized visually also. The higher denier value obtained 
in the sample was the found to be around 527 and the lowest value was found to be 278 . The average value of the linear density was found to be 458 denier.

\section{Density}

The density value of the Agave fibers measured using density bottle method, at constant temperature, i.e. $25^{\circ} \mathrm{C}$ show the values in the range of $0.475-0.497 \mathrm{~g} / \mathrm{cc}$, which appears to be the lowest among all natural cellulosic fibers and also very much lesser than the density values of the amorphous materials i.e. $1.49 \mathrm{~g} / \mathrm{cc}$ In spite of the higher degree of crystalline value, as measured by the powder XRD, the very low density values observed in the fibers, possibly, could be due to the presence of the more cylindrical type of voids present in the structure of the fibers as revealed by scanning electron microscope analysis.

\section{Degree of Crystallinity}

Powder XRD carried out at scanning rate of $2^{\circ}$ per min, for equatorial reflections, shows the two prominent peaks in the diffractogram, which reveals the crystalline nature of the sample. Intensive reflections were obtained values of $18^{\circ}$ and $22^{\circ}$, possibly due to reflections . The degree of crystallinity is found to be about $65.625 \%$ from the equatorial reflections obtained in the above scanning angles. The prominent peak obtained is $22^{\circ}$ shows very much greater than other natural cellulosic fibers.

\section{E. Moisture Value}

The moisture values of Agave Americana sample are tested. And the average moisture value is found to be $10.02 \%$.

\begin{tabular}{|c|c|}
\hline Sample & Moisture Value (\%) \\
\hline$A$ & 9.69 \\
\hline$B$ & 11.20 \\
\hline$C$ & 9.17 \\
\hline
\end{tabular}

\section{E. Strength and Elongation}

The Strength and elongation tests have been done for the Agave Americana Fiber samples. The Mean breaking strength and elongation is found to be $802.20 \mathrm{~g}$ and $6.58 \%$ respectively. The CV\% of strength and elongation is found to be $36.75 \%$ and $16 \%$ respectively.

\section{G. Thickness Test}

Thickness test is measured by fabric thickness tester. The results were $2.88 \mathrm{~mm}$ for unfinished fabric and for finished fabric it is $3.13 \mathrm{~mm}$.

\section{H.Absorbency Test}

The absorbency test is carried out by drop penetration method.The water is poured on the fabric and the rate absorption of water is noted by using stopwatch. Then the values are assessed. It is been noted that the treated fabric possess better absorbency than the untreated samples. 


\section{I.Wash Fastness Test}

Two adjacent fabrics measuring $10 \times 4 \mathrm{~cm}$ sample were taken and the piece was placed between the two adjacent fabrics and the four sides were stitched to form a composite specimen. The first piece is name as the test specimen then second piece

\section{First Piece - Agave Fabric \\ Second Piece - Cotton}

The composite specimen was placed in a container having heated $\left(40 \pm 2^{\circ} \mathrm{C}\right)$ soap solution. The material to liquor ratio 50:1 then the material is treated for 30 mins at $\left(40 \pm 2^{\circ}\right.$ C).Then the samples are cleaned, washed and dried at $60^{\circ} \mathrm{C}$. The stitches were removed along three sides. The change in color and degree of staining were assigned using geometric grey scale .It posses good wash fastness property.

\section{J. Rubbing Fastness}

The rubbing fastness of samples was determined with the help of crock meter. The test specimen measuring $14 \times 5 \mathrm{~cm}$ was taken. Another piece of $5 \times 5 \mathrm{~cm}$ undyed bleached cotton was taken. The test specimen was fixed in the crock meter. The sample posses good in dry rubbing and average in wet rubbing.

\section{Conclusion}

The Agave Americana fibers extracted from the leaves of agave plant in an eco-friendly, effective and affordable manner. In this study we have extracted the fiber from the Agave Americana leaf. The fiber extraction process done by retting process. The processed water can be used for the purpose of Bio gas. The scouring and bleaching process were carried out for the removal of impurities from the natural fiber.

The physical structure and the chemical properties of the Agave Americana fibers has been evaluated. The spinning of agave fibers were carried out in the flyer spinning machine. The fiber is too stiff so the spin ability of the fiber is poor. We expect that if the finishing process is carried out in fiber stage the spin ability of the fiber may be improved.

The weaving of agave yarn is difficult process because of the stiffness of the yarn. In the weaving process, the shed formation of 'neps' is also high during weaving. Due to these reasons there is difficult in the power loom weaving.

The agave fabric was treated with cold brand reactive dyes and the fastness properties of the fabric were good. In this project, the agave were subjected to the silicone enzyme finishing process of the fabric was made soften.

\section{Future Scope of the Project}

In this project we have made the agave yarn into fabric by handloom weaving process. There were many difficulties in the weaving process. Hence we expect that the fibers can be given softening treatment to reduce the stiffness of the fiber and it can be spunned in to yarn.

If the fiber is made softer means, the spinning and weaving process will be easier.

We have applied cold brand reactive dyes to the fabric and the fastness properties were good. We expect that the fabric can be dyed by using some natural dyes. 


\section{References}

[1] Msahli,S.: Drean, J.Y.Sakli,F. " Evaluation of the fineness of Agave Americana L.Fibres.Text.Res.J.2005,75,540-543.

[2] Mbugua, G " Determination of fibre properties of Agave Americana leaves as a textile fibre from mbaruk,Kenyatta University,2009.

[3] Carter,H.R. " The decortication of fibrous plants with special reference to the Belgian flax industry.J.Text.Inst.,236-237.

[4] Msahli, S.; Chaabouni, Y.; Sakli, F.; Drean, Y. Mechanical behavior of Agave Americana L. Fibres: Correlation between fine structure and mechanical properties. J. Appl. Sci. 3951$3957,2007$.

[5] D.S. Vijayan, A. Mohan, J. Revathy, D. Parthiban, R. Varatharajan, "Evaluation of the impact of thermal performance on various building bricks and blocks: A review", Environmental Technology \& Innovation 23 (2021) 101577, https://doi.org/10.1016/j.eti.2021.101577.

[6] S. Suhas, M.J. Silvister Raju, D.S. Vijayan , "Natural fibre reinforcement experimental study in polymer composite", Materials Today: Proceedings, , https://doi.org/10.1016/j.matpr.2020.12.051

[7] Chaabouni, Y. , Drean, J.Y. , Msahli, S. , and Sakli, F. , Morphological Characterization of Individual Fiber of Agave Americana L., Textile Res. J. 76(1), 1-8 2006. 